\title{
The dawn phenomenon in Type 1 (insulin-dependent) diabetes mellitus: magnitude, frequency, variability, and dependency on glucose counterregulation and insulin sensitivity
}

\author{
G.Perriello, P.De Feo, E. Torlone, C. Fanelli, F. Santeusanio, P. Brunetti and G. B. Bolli \\ Istituto di Patologia Medica e Metodologia Clinica, dell' Universita' degli Studi, Perugia, Italy
}

Summary. In 114 subjects with Type 1 (insulin-dependent) diabetes mellitus the nocturnal insulin requirements to maintain euglycaemia were assessed by means of i. v. insulin infusion by a Harvard pump. The insulin requirements decreased after midnight to a nadir of $0.102 \pm 0.03 \mathrm{mU} \cdot \mathrm{kg}^{-1} \cdot \mathrm{min}^{-1}$ at 02.40 hours. Thereafter, the insulin requirements increased to a peak of $0.135 \pm 0.06 \mathrm{mU} \cdot \mathrm{kg}^{-1} \cdot \mathrm{min}^{-1}$ at 06.40 hours $(p<0.05)$. The dawn phenomenon (increase in insulin requirements by more than $20 \%$ after 02.40 hours lasting for at least 90 min) was present in 101 out of the 114 diabetic subjects, and its magnitude (\% increase in insulin requirements between $05.00-07.00$ hours vs that between 01.00 03.00 hours) was $19.4 \pm 0.54 \%$ and correlated inversely with the duration of diabetes $(r=-0.72, p<0.001)$, but not with age. The nocturnal insulin requirements and the dawn phenomenon were highly reproducible on three separate nights. In addition, glycaemic control, state of counterregulation to hypoglycaemia and insulin sensitivity all influenced the magnitude of the dawn phenomenon as follows. In a subgroup of 84 subjects with Type 1 diabetes, the multiple correlation analysis showed that not only duration of diabetes $(t=-9.76, p<0.0001)$, but also $\% \mathrm{Hb}_{1}$ significantly influenced the magnitude of the dawn phenomenon $(t=2.03$, $p<0.05$ ). After 5-9 months of intensive therapy, the magnitude of the dawn phenomenon decreased from $24 \pm 2 \%$ to
$18 \pm 2 \%(p<0.05)$ in seven Type 1 diabetic subjects with initially poor glycaemic control, whereas it increased from $17 \pm 2 \%$ to $24 \pm 3 \%(p<0.05)$ in five Type 1 diabetic subjects in whom glycaemic control had deteriorated for 2 weeks. In 18 Type 1 diabetic subjects the magnitude of the dawn phenomenon correlated with the indices of adequate glucose counterregulation, namely plasma glucose concentration at the hypoglycaemic nadir $(r=-0.79)$ and the rate of plasma glucose recovery from hypoglycaemia $(r=-0.74)$ (both $p<0.01$ ). Finally, in 10 diabetic subjects in whom insulin sensitivity was examined by the euglycaemic glucose clamp technique, there was a correlation between the residual rate of hepatic glucose production $(r=0.78, p<0.005)$ as well as between the rate of peripheral glucose utilization and the magnitude of the dawn phenomenon $(r=-0.70, p<0.025)$. In conclusion, the dawn phenomenon is a very frequent event in Type 1 diabetes; its magnitude $(\sim 20 \%)$ is much lower than that indicated by previous Biostator studies; it is highly reproducible from day to day; it is influenced by the duration of diabetes, glycaemic control, state of the counterregulation system to hypoglycaemia and insulin sensitivity.

Key words: Dawn phenomenon, Type 1 (insulin-dependent) diabetes mellitus, insulin-sensitivity, glucose counterregulation, glucose turnover, growth hormone.
The dawn phenomenon is a transient increase in insulin requirements which may occur between 05.00 and 08.00 hours in people with Type 1 (insulin-dependent) diabetes mellitus [1-3], Type 2 (non-insulin-dependent) diabetes mellitus [4-8], and in non-diabetic individuals [8-10]. In subjects with Type 1 diabetes, if the increase in insulin requirement after 04.00 hours is not met, hyperglycaemia develops [11,12]. In Type 1 diabetes, considerable evidence indicates that the dawn phenomenon is the result of a transient decrease in sensitivity to insulin, both at hepatic and extrahepatic level [13], induced by nocturnal secretion of growth hormone [13-16] rather than increased clearance of insulin $[3,8,10,13,17,18]$.

Despite the number of studies published over the last few years [19], it is surprising that several clinical aspects of the dawn phenomenon in Type 1 diabetes have not yet been clarified. For example, it is not known to what extent the insulin requirements increase at dawn compared to the early night hours; how frequent is the dawn phenomenon among people with Type 1 diabetes, and how reproducible it is when examined on different occasions in the same diabetic individuals. In addition, it is not known 
whether factors such as glycaemic control, state of the counterregulation system to hypoglycaemia and insulin sensitivity, influence the dawn phenomenon. Clearly, all this information is crucial for a rational strategy of intensive insulin therapy for the nocturnal hours of subjects with Type 1 diabetes, which aims at pre-breakfast nearnormoglycaemia while avoiding nocturnal hypoglycaemia [20,21].

The present series of studies were undertaken to assess: (1) the magnitude; (2) the frequency of the dawn phenomenon in a large population of people with Type 1 diabetes; (3) how reproducible is the dawn phenomenon in the same diabetic individuals; (4) the influence of factors such as glycaemic control, state of the counterregulation system to hypoglycaemia and insulin sensitivity on the dawn phenomenon.

\section{Subjects and methods}

\section{Subjects}

Between 1980 and 1988, 114 subjects with Type 1 diabetes ( 68 men, 46 women) were studied after fully informed consent was obtained. The subjects aged $17-56$ years ( $31 \pm 2$ years, mean $\pm S E M)$, had a duration of diabetes of $0.1-31$ years $(6.9 \pm 0.6$ years). With the exception of 11 subjects with duration of diabetes $<1$ year, who had detectable, although subnormal plasma C-peptide concentrations, the remaining 103 subjects had no residual endogenous insulin secretion as assessed by the plasma C-peptide response to intravenous glucagon [22]. Their percent $\mathrm{HbA}_{1 \mathrm{c}}$ [23] was $8.64 \pm 0.56 \%$ (normal range $5.1-6.9 \%$ ) and the body mass index (BMI) was $22.7 \pm 0.55 \mathrm{~kg} / \mathrm{m}^{2}$. All subjects were on a therapeutic regimen of two or three daily injections of insulin (mixture of regular and intermediate-acting insulin at breakfast and dinner; or regular insulin at breakfast and lunch, and a mixture of regular and intermediateacting insulin at dinner), with the exception of nine subjects who were treated with four daily insulin injections (regular insulin at each meal, and intermediate-acting insulin at bedtime). The subjects were healthy apart from their diabetes and did not present clinically overt diabetic complications. None of the subjects at the time of the study were given any other drug treatment apart from insulin.

\section{Study design}

To assess the magnitude and the frequency of the dawn phenomenon, the overnight insulin requirements were assessed retrospectively in all 114 diabetic subjects, the majority of whom had participated in previously reported studies $[3,24-31]$. Intermediate-acting insulin was withdrawn for at least $48 \mathrm{~h}$ prior to the studies and the subjects were injected with regular insulin at breakfast, lunch, dinner, bedtime, and at 03.00 hours based on capillary blood glucose concentration. On the day of the study, the last s. c. injection of regular insulin was given at lunch. Thereafter, between 17.00-17.30 hours the subjects rested in bed, and a 18-gauge catheter-needle was placed into a superficial forearm vein for infusion of regular insulin (diluted to a final concentration of $\sim 3.5 \mu \mathrm{mol} / 1$ in $0.9 \% \mathrm{NaCl}$ solution containing $0.5 \%$ human albumin, Immuno S. p. A., Pisa, Italy) by means of a syringe pump (Harvard Apparatus, South Natick, Mass, USA). A 21-gauge butterfly needle was inserted retrogradely into a dorsal vein of the contralateral hand which was kept warm in a thermoregulated plexiglass box at $65^{\circ} \mathrm{C}$ to ensure arterialization of venous blood [32]. This line was used for intermittent blood sampling and bedside measurement of plasma glucose concentration every $2.5-10 \mathrm{~min}$.
Between 18.00-18.30 hours the subjects consumed a standard meal (725 kcal, $45 \%$ carbohydrate, $30 \%$ fat, $25 \%$ protein). Insulin was infused at variable rates to prevent an increase in the plasma glucose concentration above $10 \mathrm{mmol} / \mathrm{h}$ for the first $2 \mathrm{~h}$ after the meal. Thereafter, between 20.30 and 08.00 hours the next morning, the plasma glucose concentration was maintained between 4.5 and $5.5 \mathrm{mmol} / 1$ by infusing insulin according to a previously described algorithm [3]. Adjustments in the insulin infusion rate were made every 2.5-10 min.

To assess the intraindividual variability of the dawn phenomenon, 29 diabetic subjects [26-28] were restudied on two additional occasions, separated by 6-30 days, and the nocturnal insulin requirements were reassessed as described above.

To assess the effects of glycaemic control on the dawn phenomenon, first, the correlation between the $\% \mathrm{HbA}_{1}$ and the increase in insulin requirements at dawn was examined in 84 diabetic subjects in whom glycosylated haemoglobin had always been measured with the same technique [33]. Second, 13 subjects with initially poor glycemic control were studied before and after either improvement (for 5-9 months, $n=7$ ) or no change (for 6-8 months, $n=6$ ) in glycaemic control [29], whereas, in five patients with initially good control during intensive insulin therapy, the nocturnal insulin requirements were studied before and two weeks after deliberate deterioration of their blood glucose control, as previously reported [29].

To assess the effects of the state of the counterregulation system on the dawn phenomenon, the increase in insulin requirements at dawn and the indices of adequate counterregulation, namely plasma glucose nadir and post-nadir plasma glucose recovery rate in a standardized insulin-infusion test, were analysed in 18 subjects with Type 1 diabetes [28].

To assess the effect of insulin sensitivity on the dawn phenomenon, insulin sensitivity was studied in 10 subjects by means of the euglycaemic-hyperinsulinaemic glucose clamp technique [34] after assessing their nocturnal insulin requirements and normalizing plasma glucose concentration over the previous $12 \mathrm{~h}$, as recently described [13]. The clinical features of these 10 subjects [ 7 men, 3 women, age $21-55$ years ( $29 \pm 2$ years), diabetes duration $1.8-2.7$ years $(7.2 \pm 1.3)$, BMI $21-25 \mathrm{~kg} / \mathrm{m}^{2} \quad\left(22.2 \pm 0.8 \mathrm{~kg} / \mathrm{m}^{2}\right)$, $\left.\% \mathrm{HbA}_{1 \mathrm{c}} 7.0-9.3 \%(8.2 \pm 0.7 \%)\right]$ did not differ significantly from those of the remaining 104 subjects of this study. In the clamp studies, hyperinsulinaemia was induced by two sequential steps, $2 \mathrm{~h}$ each, of insulin infusion at the rate of $0.25 \mathrm{mU} \cdot \mathrm{kg}^{-1} \cdot \mathrm{min}^{-1}$ and $1 \mathrm{mU} \cdot \mathrm{kg}^{-1} \cdot \mathrm{min}^{-1}$, respectively. A primed $(18 \mu \mathrm{Ci})$ continuous $(0.18 \mu \mathrm{Ci} / \mathrm{min})$ infusion of $3-{ }^{3} \mathrm{H}$-glucose (New England Nuclear, Boston, Mass, USA) was started at $-3 \mathrm{~h}$ (between 07.00 and 08.00 hours) and continued until the end of the clamp studies (between 14.00 and 15.00 hours) to measure the rate of endogenous (hepatic) glucose production.

\section{Methods}

Plasma glucose was measured by the glucose oxidase method (Beckman Glucose Analyzer, Beckman Instruments, Fullerton, Calif., USA). Glucose specific activity [35] and plasma free insulin [36] were determined by previously decribed methods. Polyethyleneglycol precipitation of plasma insulin antibodies was performed soon after drawing blood, as previously described [31].

Calculations, definition of the dawn phenomenon and its magnitude. Plasma glucose concentration and overnight insulin requirements were analysed as the mean values over 20 min periods. In these studies, the dawn phenomenon was defined as an increase by more than $20 \%$ in the insulin infusion rates required to maintain euglycaemia after 02.40 hours and lasting for at least $90 \mathrm{~min}$. This definition was adopted because in previous studies in which the dawn phenomenon was prevented by suppression of nocturnal spikes of growth hormone secretion [13], the nocturnal insulin infusion rates required to maintain euglycaemia after 02.00 hours increased by less than $10 \%$ as compared to the insulin infusion rates before 
02.00 hours. The magnitude of the dawn phenomenon was defined as the percent increase in the insulin requirements occurring between 05.00 and 07.00 hours as compared to those occurring between 01.00 and 03.00 hours.

Glucose turnover. Rates of glucose production and utilization at baseline during the first $2 \mathrm{~h}$ of the euglycaemic-hyperinsulinaemic clamp studies (insulin infusion rate $0.25 \mathrm{mU} \cdot \mathrm{kg}^{-1} \cdot \mathrm{min}^{-1}$ ) were calculated with the use of the non-steady-state equations of De Bodoet al. [37] and were "smoothed" according to the method of Miles et al. [38]. During the last $2 \mathrm{~h}$ of the euglycaemic-hyperinsulinaemic clamp experiments at the insulin infusion rate of $1 \mathrm{mU} \cdot \mathrm{kg}^{-1} \cdot \mathrm{min}^{-1}$, the calculated rate of hepatic glucose production yielded negative numbers [39]. Thus, it was assumed that in this second part of the clamp, the hepatic glucose production was fully suppressed [40] and that therefore the rate of exogenous cold glucose infusion equalled the whole body glucose utilization. Consequently, in the second part of the clamp studies at high insulin infusion rate, the rate of cold glucose infusion and not the isotopically calculated glucose turnover, was considered as the real rate of peripheral glucose utilization, as previously reported [13].

\section{Statistical analysis}

Data are given as mean \pm SEM and were evaluated by analysis of variance corrected for repeated measures, and where appropriate, two-tailed, paired $t$-test. Regressions were calculated by multiple regression analysis [41]. Statistical analysis was performed using CSS 2.1 software (Statsoft, Inc., Tulsa, Okla, USA).

\section{Results}

\section{Overnight insulin requirements in Type 1 diabetes (Fig.1)}

The insulin infusion rate required to maintain euglycaemia decreased continuously after midnight from $0.113 \pm 0.05 \mathrm{mU} \cdot \mathrm{kg}^{-1} \cdot \mathrm{min}^{-1}$ to a nadir value of $0.102 \pm$ $0.03 \mathrm{mU} \cdot \mathrm{kg}^{-1} \cdot \mathrm{min}^{-1}$ at 02.40 hours. Thereafter, insulin requirements increased progressively by $30 \%$ to a peak of $0.135 \pm 0.06 \mathrm{mU} \cdot \mathrm{kg}^{-1} \cdot \mathrm{min}^{-1}$ at 06.40 hours $(p<0.05$ vs the nadir value of 02.40 hours), and remained increased until 08.00 hours $\left(0.123 \pm 0.04 \mathrm{mU} \cdot \mathrm{kg}^{-1} \cdot \mathrm{min}^{-1}, p<0.05\right.$ vs the nadir value at 02.40 hours). As a result of the infu-

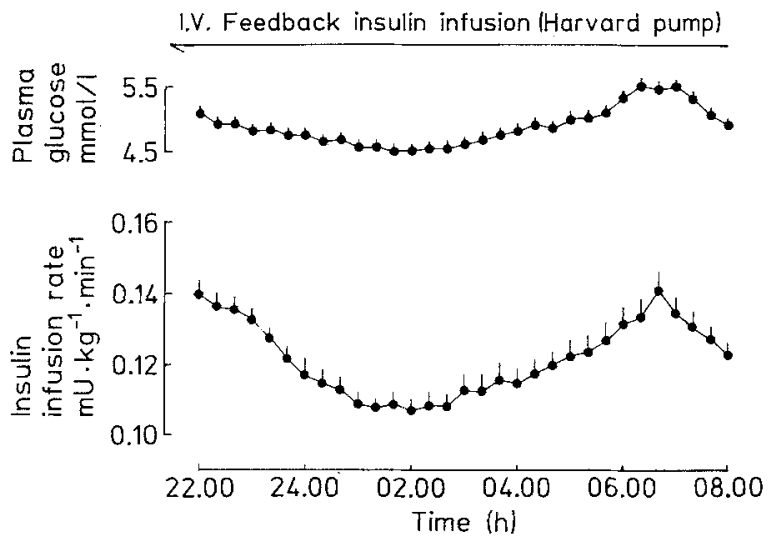

Fig.1. Nocturnal insulin requirements to maintain euglycaemia in 114 subjects with Type 1 (insulin-dependent) diabetes mellitus infused with intravenous insulin at variable rate by means of a Harvard pump. Top panel-plasma glucose; lower panel-insulin infusion rate (mean \pm SEM)

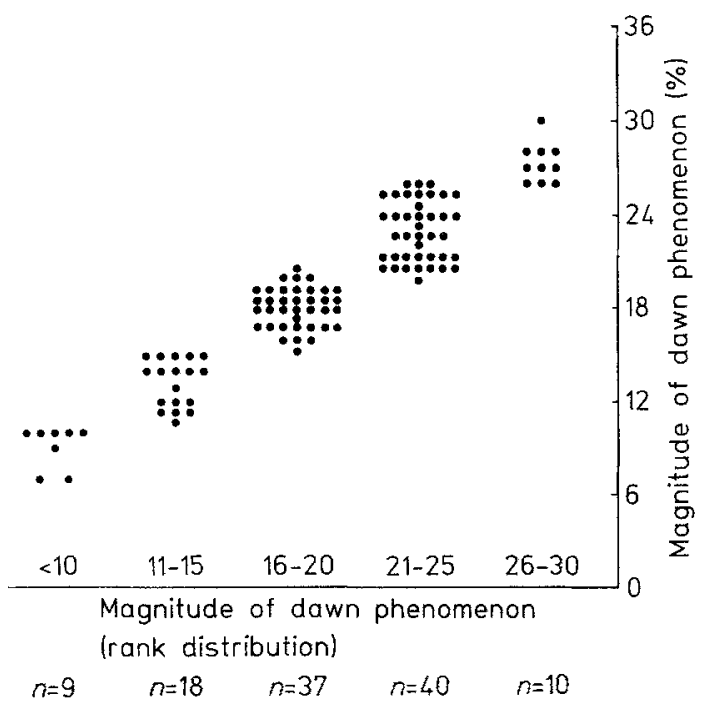

Fig. 2. Distribution of the magnitude of the dawn phenomenon (percent increase in the mean insulin requirements between 05.00 and 07.00 hours as compared to those occurring between 01.00 and 03.00 hours) in the 114 subjects with Type 1 diabetes divided into groups according to intervals of $5 \%$ difference

sion of insulin at variable rate, plasma glucose concentrations remained constant from midnight to 04.40 hours $(4.82 \pm 0.10 \mathrm{mmol} / \mathrm{l})$. After which they increased by $10 \%$ between 05.00 and 08.00 hours despite the increase in insulin infusion rate $(5.21 \pm 0.12 \mathrm{mmol} / \mathrm{l}, p<0.05$ vs the midnight -04.40 hours value) (Fig. 1 ).

\section{Frequency, timing and magnitude of the dawn phenomenon (Figs. 2,3)}

The dawn phenomenon was present in 101 out the 114 subjects $(89 \%)$ and it started at $05.15 \pm 0.12$ hours (range $03.40-06.40$ hours) and lasted for $1.9 \pm 0.08 \mathrm{~h}$ $(1.2-2.5 \mathrm{~h})$ with a magnitude of $19.4 \pm 0.54 \%(6-31 \%)$. The subjects were divided into groups according to a $5 \%$ difference in the magnitude of the dawn phenomenon

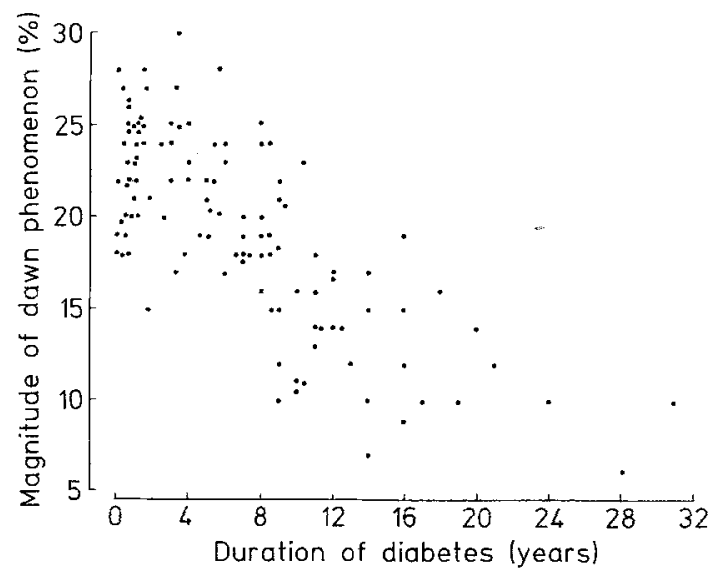

Fig.3. Scatter plot of duration of diabetes and the magnitude of the dawn phenomenon (defined in the legend to Fig.2) in the 114 subjects with Type 1 diabetes. For multiple regression analysis see text 

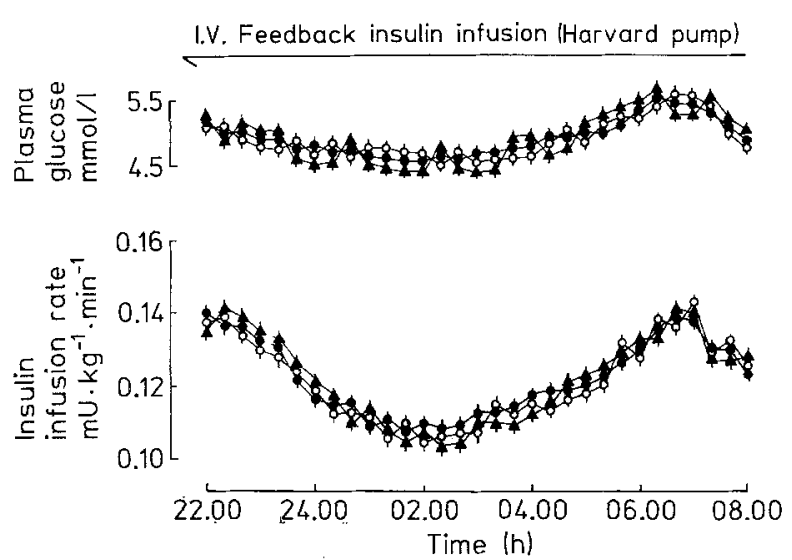

Fig.4. Reproducibility of overnight insulin requirements and dawn phenomenon in 29 subjects with Type 1 diabetes studies on three separate occasions ( $\boldsymbol{\Delta}$ study 1,0 study $2, \bullet$ study 3 )

(Fig. 2). Compared to 37 subjects in whom the magnitude of the dawn phenomenon ranged between 16 and $20 \%$, the magnitude in 50 subjects was greater than $20 \%$, whereas it was less than $16 \%$ in the remaining 27 subjects. The 50 subjects with the greatest magnitude of dawn phenomenon $(24 \pm 0.3 \%)$ had a shorter duration of diabetes (3.6 \pm 0.4 vs $13.6 \pm 1.3$ years), less optimal glycaemic control $\left(\mathrm{HbA}_{1}, 11.9 \pm 0.3\right.$ vs $8.7 \pm 0.3 \%$, both $\left.p<0.05\right)$, but their age was not significantly different from that the rest of the subjects. The scatter plot of duration of diabetes and magnitude of dawn phenomenon is shown in Fig-

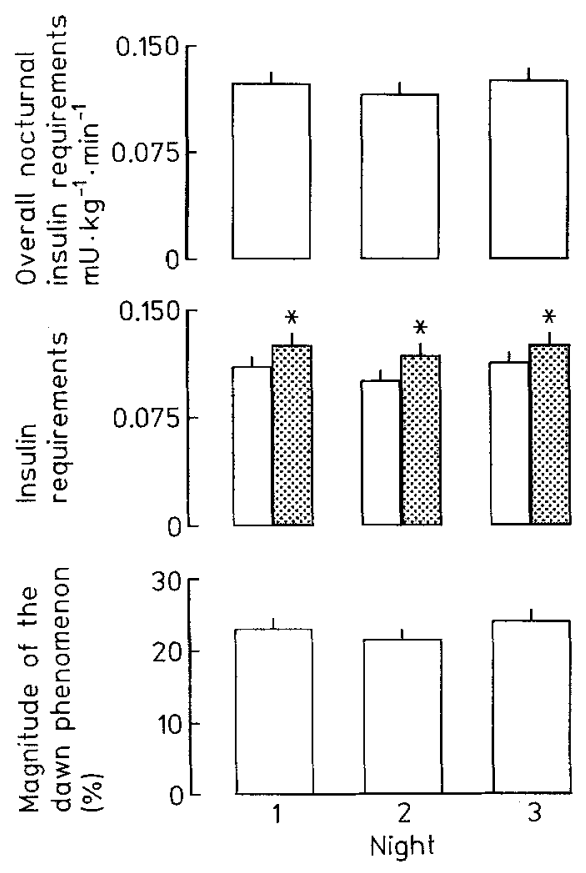

Fig.5. Reproducibility of the dawn phenomenon. The insulin requirements were superimposable on three different nights, when analysed as overall insulin infusion rates from midnight to 08.00 hours (top panel), as well as in the periods from 01.00 to 03.00 hours (open bar) and from 05.00 to 07.00 hours (shaded bar) (centre panel), and finally when calculated as percent increases in the insulin requirements between 05.00 and 07.00 hours as compared to those occurring between 01.00 and 03.00 hours (magnitude of the dawn phenomenon, bottom panel) $\left({ }^{*} p<0.05\right)$

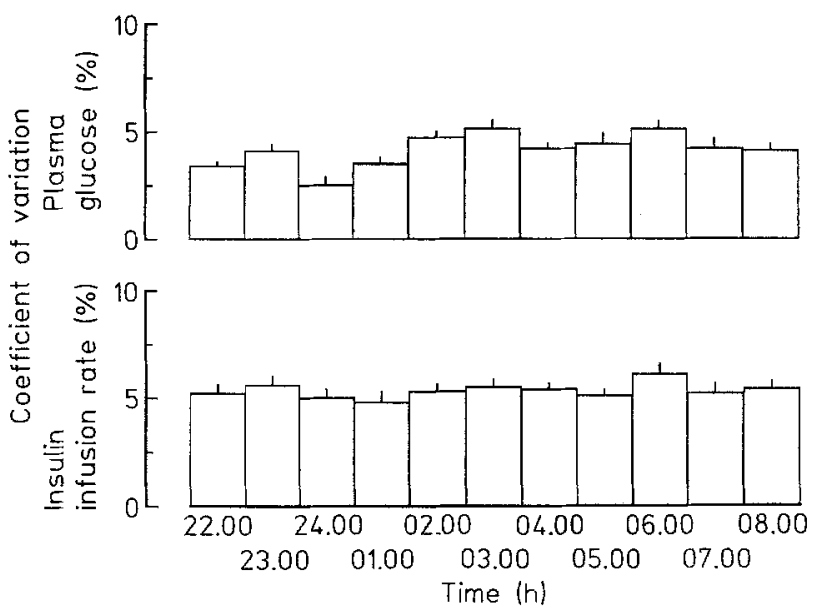

Fig. 6. Coefficients of variations of mean hourly plasma glucose concentration and insulin infusion rates to maintain euglycaemia in 29 subjects with Type 1 diabetes studied on three different nights (mean \pm SEM)

ure 3. Using the correlation analysis, no effects of age $(r=-0.28, p<0.05)$, but a strong effect of duration of diabetes on the magnitude of the dawn phenomenon was found $(r=-0.72, p<0.001)$.

\section{Intraindividual variability of the dawn phenomenon (Figs. 4-6)}

In the experiments in which the same 29 subjects were studied on three different nights, their insulin requirements were virtually superimposable from study to study, as was the plasma glucose concentration (Fig.4).

In these studies the overall nocturnal insulin requirements were no different on the three separate nights $\left(0.121 \pm 0.06 \mathrm{mU} \cdot \mathrm{kg}^{-1} \cdot \mathrm{min}^{-1}, 0.18 \pm 0.04 \mathrm{mU} \cdot \mathrm{kg}^{-1}\right.$. $\mathrm{min}^{-1}$, and $0.124 \pm 0.05 \mathrm{mU} \cdot \mathrm{kg}^{-1} \cdot \mathrm{min}^{-1}$, nights 1,2 and 3 , respectively, $p=\mathrm{NS}$ ) (Fig. 5, top panel). In addition, the increases in insulin requirements occurring between 05.00 and 07.00 hours compared to those occurring between 01.00 and 03.00 hours was highly reproducible on the three different nights of the studies (Fig. 5, center and bottom panels). Finally, the low variability of the nocturnal insulin requirements and the dawn phenomenon is also indicated by the coefficient of variation of mean hourly plasma glucose concentration and insulin infusion rates, which in individual subjects never exceeded 10\% (Fig. 6).

\section{Effect of glycaemic control on the dawn phenomenon} (Figs. 7, 8)

In Figure 7 the magnitude of the dawn phenomenon and $\% \mathrm{HbA}_{1}$ are shown as scatter plots in 84 diabetic subjects in whom $\mathrm{HbA}_{1}$ was always determined with the same method [33]. The multiple regression analysis performed to examine the effects of duration of diabetes, $\% \mathrm{HbA}_{1}$ (glycaemic control), and age (independent variables) on the magnitude of the dawn phenomenon (dependent variable), showed a bighly significant multiple R (0.76, 


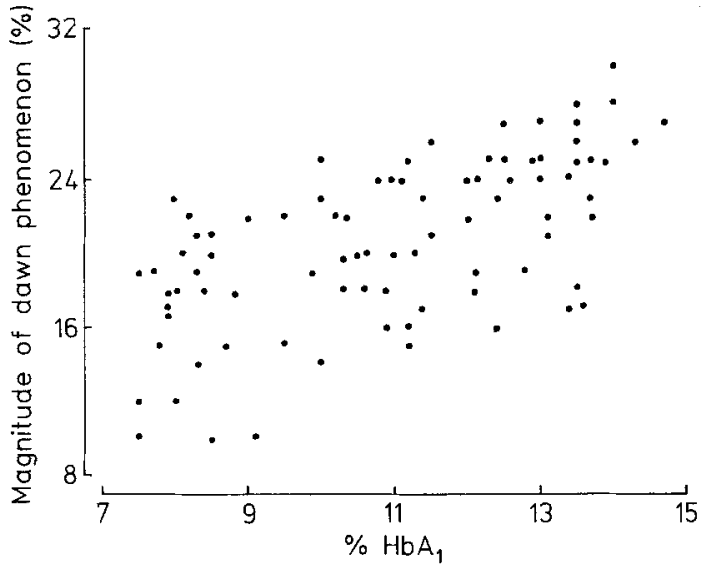

Fig. 7. Scatter plot of the percent $\mathrm{HbA}_{1}$, and the magnitude of dawn phenomenon (see legend to Fig. 2 for definition) in 84 subjects with Type 1 diabetes in whom the $\mathrm{HbA}_{1}$ had always been measured with the same method [33]

$\mathrm{F}(3.80)=36.52, p<0.0001)$ with the following coefficients: intercept $=17.93, \mathrm{~B}_{1}=-0.53, \mathrm{~B}_{2}=0.36, \mathrm{~B}_{3}=0.06$. Although the highest contribution to multiple $\mathrm{R}$ was due to duration of diabetes $(t=-9.76, p<0.0001), \% \mathrm{HbA}_{1}$ also contributed significantly $(t=2.03, p<0.05)$ to the final estimates, whereas age did not contribute significantly to the model. Thus, the poorer the glycaemic control, the greater the dawn phenomenon.

In the seven diabetic subjects who were initially in poor glycaemic control, institution of intensive insulin therapy for 5-9 months improved glycaemic control ( $\mathrm{HbA}_{1}$ fell from $12.4 \pm 0.2 \%$ to $7.9 \pm 0.2 \%, p<0.001$ ) and resulted in a decrease in the magnitude of the dawn phenomenon from $24 \pm 2 \%$ to $18 \pm 2 \%(p<0.05)$. On the other hand, in the six subjects in whom intensive insulin therapy was not instituted and glycaemic control remained similarly poor before and after $6-8$ months of observation $\left(\mathrm{HbA}_{1} 12.4 \pm 0.1 \%\right.$ and $12.3 \pm 0.2 \%$, respective-

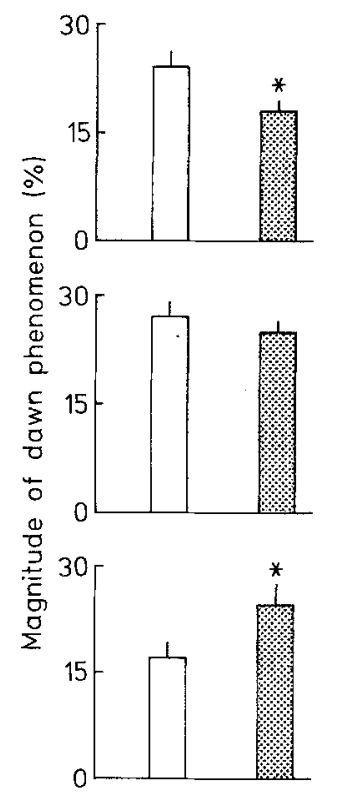

Fig. 8. Effect of improved [upper panel, 7 subjects with Type 1 diabetes, before (open bar) and 5-9 months after good glycaemic control (shaded bar)], unchanged [centre panel, 6 subjects with Type 1 diabetes, before (open bar) and 6-8 months after unchanged glycaemic control (shaded bar)] or deteriorated glycaemic control [lower panel, 5 subjects with Type 1 diabetes, before (open bar) and 2 weeks after poor glycaemic control (shaded bar)], on the magnitude of the dawn phenomenon (see legend to Fig. 2 for definition $(* p<0.05)$ ly, $p=$ NS), the magnitude of the dawn phenomenon did not change (27 $\pm 3 \%$ and $25 \pm 2 \%$, respectively, $p=\mathrm{NS}$ ). Finally, in the five diabetic subjects who were switched from intensive to non-intensive insulin therapy for two weeks, $\mathrm{HbA}_{1}$ increased from $7.9 \pm 0.2 \%$ to $9.1 \pm 0.2 \%$ [22] and also the magnitude of the dawn phenomenon (from $17 \pm 2 \%$ to $24 \pm 3 \%$ ) (both $p<0.05$ ). Thus, improvement in glycaemic control attenuated, and deterioration exaggerated the magnitude of the dawn phenomenon, respectively, whereas unchanged glycaemic control had no effect (Fig. 8).

\section{Effects of the state of the counterregulatory system to hypoglycaemia on the dawn phenomenon}

In the 18 diabetic subjects studied, the magnitude of the dawn phenomenon was correlated inversely with the indices of adequate glucose counterregulation [28], namely plasma glucose concentration at hypoglycaemic nadir $(r=-0.79)$ and the rate of post-nadir plasma glucose recovery from hypoglycaemia $(r=-0.74)$ (both $p<0.01)$. Thus, the more adequate the counterregulatory response to hypoglycaemia, the more pronounced the dawn phenomenon and vice-versa.

\section{Effect of insulin sensitivity on the dawn phenomenon} (Fig. 9)

In the 10 diabetic subjects in whom insulin sensitivity was examined by means of the euglycaemic-hyperinsulinaemic glucose clamp, there was a correlation between the residual rate of hepatic glucose production (calculated during the first $2 \mathrm{~h}$ of the clamp studies at the plasma free insulin concentration of $143 \pm 21 \mathrm{pmol} / \mathrm{l}$ ) and the magni-

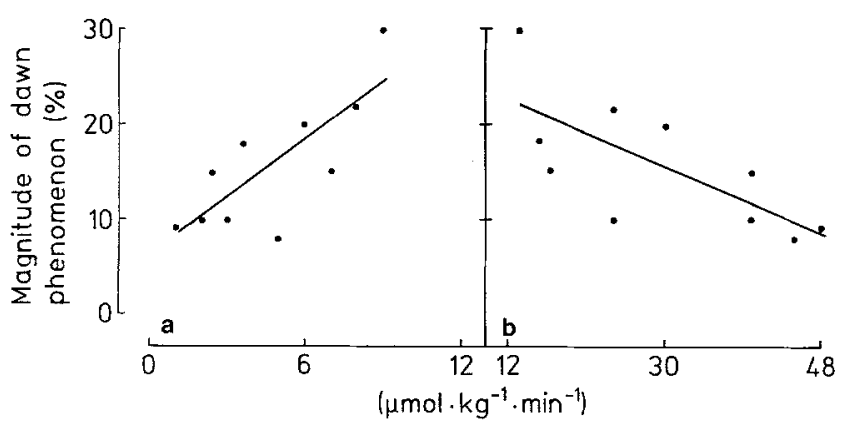

Fig.9 a, b. The lower the hepatic and peripheral insulin sensitivity, the greater the dawn phenomenon. Correlation between insulin sensitivity (hepatic and peripheral) and the magnitude of the dawn phenomenon (see legend to Fig. 2 for definition) in 10 subjects with Type 1 diabetes. Insulin sensitivity was assessed by means of the euglycaemic clamp technique at low insulin infusion rate $\left(0.25 \mathrm{mU} \cdot \mathrm{kg}^{-1} \cdot \mathrm{min}^{-1}\right)$ and high insulin infusion rate $\left(1 \mathrm{mU} \cdot \mathrm{kg}^{-1}\right.$. $\min ^{-1}$ ). a) The greater the hepatic glucose production (calculated from the clamp studies at low insulin infusion rate), the greater the magnitude of the dawn phenomenon $(\mathrm{y}=6.35+1.99 \mathrm{x}, r=0.78$, $p<0.005)$. b) The lower the increase in peripheral glucose utilization (calculated from the clamp studies at high insulin infusion rates), the greater the magnitude of the dawn phenomenon $(y=27-$ $0.38 \mathrm{x}, r=-0.70, p<0.0025$ ) 
tude of the dawn phenomenon $(r=0.78, p<0.005)$, and between the rate of peripheral glucose utilization (calculated over the last $2 \mathrm{~h}$ of the clamp studies at the plasma free insulin concentration of $582 \pm 43 \mathrm{pmol} / \mathrm{l}$ ) and the magnitude of the dawn phenomenon $(r=-0.70$, $p<0.025$ ) (Fig.9). Thus, the greater the insulin sensitivity, both at the hepatic and extrahepatic level, the smaller the magnitude of the dawn phenomenon and vice-versa.

\section{Discussion}

The present studies indicate that the dawn phenomenon is a very frequent event in subjects with Type 1 diabetes mellitus; its magnitude is lower than initially indicated by previous Biostator studies; it is highly reproducible from day to day, and it is influenced by factors such as duration of diabetes, quality of antecedent glycaemic control, state of counterregulation system to hypoglycaemia and insulin sensitivity.

In the past few years, a number of studies have examined the dawn phenomenon in people with Type 1 diabetes [19]. In those studies it was difficult to establish the frequency, the intra-subject variability and other clinically important aspects of the dawn phenomenon, either because the number of subjects examined was small [3, $42]$, or the artificial endocrine pancreas Biostator was used $[2,4,11,14,16,43,44]$. In fact, because of the progressive loss of the biological activity of the insulin infused over time by the peristaltic pump of the Biostator $[17,45]$, it is likely that in the previous Biostator studies - at least in those in which albumin was apparently not added to the insulin infusate $[2,4,11,43,44]$ - the magnitude of the dawn phenomenon has been overestimated.

In the present studies, a large population of subjects with Type 1 diabetes $(n=114)$ was examined. The nocturnal insulin requirements were studied during insulin delivery by means of a Harvard syringe pump, an approach which does not result in a loss of the biological activity of the insulin infused over time $[17,45]$. Under these conditions, the following observations were made.

First, the insulin requirements after midnight initially decreased to a nadir value of $0.102 \pm 0.03 \mathrm{mU} \cdot \mathrm{kg}^{-1}$. $\mathrm{min}^{-1}$ at 02.40 hours and subsequently increased to $0.135 \pm 0.06 \mathrm{mU} \cdot \mathrm{kg}^{-1} \cdot \mathrm{min}^{-1}$ at 06.40 hours. Thus, in the present studies, the peak increase at dawn as compared to the early night hours was $30 \%$, whereas the magnitude of the dawn phenomenon (percent increase in the insulin requirements occurring between 05.00 and 07.00 hours as compared to those occurring between 01.00 and $03.00 \mathrm{~h}$ ) was $20 \%$. It is likely that the magnitude of the dawn phenomenon in these experiments has been underestimated, because the plasma glucose concentration increased after 05.00 hours despite the increase in insulin infusion rate, implying that the insulin requirements at that time of day were in fact greater than those indicated by our experiments. Nevertheless, the figures of the magnitude of the dawn phenomenon observed in the present study are three times smaller than those suggested by early Biostator studies $[2,4]$ in which the insulin requirements after 06.00 hours were found to increase by as much as $100 \%$ compared to those of the early night hours - an overestimation most likely due to the previously discussed Biostator artifact $[17,45]$. Interestingly, the nadir to peak increase in nocturnal insulin requirements observed in the present studies in Type 1 diabetes is similar to that observed in previous studies in Type 2 diabetes [6] as well as in normal non-diabetic subjects [10]. This finding suggests that the dawn phenomenon is not a specific feature of diabetes, but rather it is a physiological event which is part of a circadian variation in insulin sensitivity $[10,46]$.

Second, the dawn phenomenon occurred in virtually all of the subjects examined (89\%). Thus, the dawn phenomenon is a persistent event in subjects with Type 1 diabetes.

Third, the nocturnal insulin requirements in general and the dawn phenomenon in particular were remarkably reproducible from day to day in the same diabetic subjects. It is likely that the results of a previous study in which the opposite conclusion was reached [4], were due to the Biostator artifact, i. e. to the unpredictable losses of biologically active insulin infused by the Biostator on different nights. In fact, when human albumin was added to the insulin infusate delivered by the Biostator, a procedure which prevents loss of biological activity of the infused insulin [17,45], the dawn phenomenon was found to be reproducible even using the Biostator [47]. Thus, since the nocturnal insulin requirements and the dawn phenomenon are remarkably reproducible from day to day, it is likely that the clinical observation of the large intraindividual day-to-day variability of fasting plasma glucose concentration in subjects with Type 1 diabetes treated with s.c. insulin injections [48], is explained by the large variability of absorption of s. c. injected insulin on the previous evening [21], rather than by the variability of the dawn phenomenon.

Fourth, in the present studies it was found that the quality of antecedent blood glucose control is an important factor for the magnitude of the dawn phenomenon, i.e., poor glycaemic control is associated with exaggerated, whereas good glycaemic control with attenuated dawn phenomenon. Since the dawn phenomenon is basically a difference in insulin sensitivity between the early night and early morning hours [13], and since glycaemic control profoundly influences insulin action in Type 1 diabetes [49], it is likely that the effects of either poor or good glycaemic control on the dawn phenomenon observed in the present studies are the result of augmented or attenuated insulin resistance, respectively, according to the concept of down- or up-regulation of glucose transporters by prevailing blood glucose concentration [50]. In this regard, the results of the present study might account for the observation that subjects with Type 1 diabetes undergoing intensive insulin therapy barely exhibit a dawn phenomenon [51].

Fifth, in the present studies the ability to counterregulate to hypoglycaemia in a standardized insulin infusion test was found to be of importance for the magnitude of the dawn phenomenon. Subjects with inadequate counterregulation had a less pronounced dawn phenomenon as compared to those with adequate counter- 
regulation. It is likely that the chronically impaired secretion of counterregulatory hormones glucagon, epinephrine, growth hormone and cortisol observed in this group explains their attenuated dawn phenomenon [28]. Since impaired counterregulation is a function of diabetes duration [25], as indeed it was in the 18 subjects examined in these experiments [29], it is likely that the finding of the inverse relationship between the diabetes duration and magnitude of the dawn phenomenon of Figure 3 in the present studies might be explained by the loss of secretion of counterregulatory hormones and greater insulin sensitivity in long-term diabetes. Thus, the present studies indicate that the longer the duration of Type 1 diabetes, the greater the impairment in the secretion of counterregulatory hormones, and the smaller the dawn phenomenon.

Sixth, insulin sensitivity both at hepatic and extrahepatic level was found to be inversely correlated with the magnitude of the dawn phenomenon, i. e., the less insulinsensitive the subjects were, the more marked the dawn phenomenon was and vice-versa. It is likely that factors such as glycaemic control and state of counterregulation which in these studies have been found to have important effects on the dawn phenomenon, might do so primarily by influencing insulin action. In subjects with Type 1 diabetes the plasma free insulin concentrations in the early morning hours usually range between 100 and $200 \mathrm{pmol} / 1[52,53]$. On the other hand, when the plasma insulin concentration was increased in this range during the clamp experiments of the present studies, only glucose production, but not glucose utilization was affected. Thus, it is likely that decreased insulin sensitivity at the liver, rather than at the peripheral level, plays the primary role in the pathogenesis of the dawn phenomenon in Type 1 diabetes, as recently suggested [13], at least in the fasting (pre-breakfast) period.

In conclusion, the present studies demonstrate that the dawn phenomenon is a very frequent and reproducible event in Type 1 diabetes mellitus, as long as factors which usually influence insulin action remain constant. However, should for any reason insulin action either improve or deteriorate, an attenuation or exaggeration of the dawn phenomenon, respectively, will occur. Overall, the magnitude of the dawn phenomenon is smaller than that indicated by previous Biostator studies. Further studies are needed to establish the extent to which the dawn phenomenon contributes to pre-breakfast hyperglycaemia in Type 1 diabetes.

Acknowledgements. This work was supported by the Consiglio Nazionale delle Ricerche (C.N.R. grants 89.02879.04 and 89.02440.04). The Authors are grateful to Drs. P. Reboldi and P. Compagnucci for their critical suggestions in preparing this manuscript. The editorial assistance of Ms. P. Boyce, and the support by le Chateau Montebello, Quebec, Canada, are gratefully acknowledged.

\section{References}

1. Deckert T, Lorup B (1976) Regulation of brittle diabetes by a pre-planned insulin infusion programme. Diabetologia 12: 573-579
2. Clarke WL, Haymond MW, Santiago JV (1980) Overnight basal requirements in fasting insulin-dependent diabetics. Diabetes 29: 78-80

3. De Feo P, Perriello G, Ventura M, Calcinaro F, Basta G, Lolli C, Cruciani C, Dell'Olio A, Santeusanio F, Brunetti P, Bolli GB (1986) Studies on overnight insulin requirements and metabolic clearance rate of insulin in normal and diabetic man: relevance to the pathogenesis of the dawn phenomenon. Diabetologia 29: 475-480

4. Bolli GB, Gerich JE (1984) The "Dawn Phenomenon"- a common occurrence in both non-insulin-dependent and insulin-dependent diabetes mellitus. N Engl J Med 310: 746-750

5. Atiea JA, Ryder RRJ, Vora J, Owens DR, Luzio SD, Williams S, Hayes TM (1987) Dawn phenomenon: its frequency in noninsulin-dependent diabetic patients on conventional therapy. Diabetes Care 10: 461-465

6. Dimitriadis G, Vlachonikolis IG, Hatziagellaki E, Linos A, Kodonouri O, Alexopoulos E, Raptis S (1988) The dawn phenomenon in patients with type II diabetes mellitus. Diab Nutr Metab 1: $37-41$

7. Taskinen MR, Sane T, Helve E, Karonen SL, Nikkila EA, YkiJarvinen H (1989) Bedtime insulin for suppression of overnight free-fatty acid, blood glucose, and glucose production in NIDDM. Diabetes 38: 580-588

8. Shapiro T, Vancauter E, Tillil H, Rubenstein A, Polonsky $\mathrm{K}$ (1989) The "dawn phenomenon" in NIDDM: an all night decrease in glucose tolerance. Diabetes 38 [Suppl 2]:3A

9. Schmidt MI, Lin QX, Gwynne JT, Jacob S (1984) Fasting early morning rise in peripheral insulin: evidence of the dawn phenomenon in nondiabetics. Diabetes Care 7: 32-35

10. Bolli GB, De Feo P, De Cosmo S, Perriello G, Ventura M, Calcinaro F, Lolli C, Campbell P, Brunetti P, Gerich JE (1984) Demonstration of a dawn phenomenon in normal human volunteers. Diabetes 33: 1150-1153

11. Campbell PJ, Bolli GB, Cryer PE, Gerich JE (1985) Sequence of events during development of the dawn phenomenon in insulindependent diabetes mellitus. Metabolism 34: 1100-1104

12. Koivisto VA, Yki-Yarvinen H, Helve E, Karonen SL, Pelkonen $\mathrm{R}$ (1986) Pathogenesis and prevention of the dawn phenomenon in diabetic patients treated with CSII. Diabetes 35: 78-82

13. Perriello G, De Feo P, Torlone E, Fanelli C, Santeusanio F, Brunetti P, Bolli GB (1990) Nocturnal spikes of growth hormone secretion cause the dawn phenomenon in Type 1 diabetes mellitus by decreasing hepatic (and extrahepatic) sensitivity to insulin in the absence of insulin waning. Diabetologia 33: $52-59$

14. Campbell PJ, Bolli GB, Cryer PE, Gerich JE (1985) Pathogenesis of the dawn phenomenon in patients with insulin-dependent diabetes mellitus: accelerated glucose production and impaired glucose utilization due to nocturnal surges in growth hormone secretion. N Engl J Med 312: 1473-1479

15. Davidson MB, Harris MD, Ziel FH, Rosenberg CS (1988) Suppression of sleep-induced growth hormone secretion by anticholinergic agents abolishes dawn phenomenon. Diabetes 37: 166-171

16. Boyle PJ, Avogaro A, Smith L, Shah LD, Bier DM, Cryer PE, Santiago JU (1989) Absence of the dawn phenomenon and abnormal lipolysis in GH deficient IDDMs. Diabetes 38 [Suppl.2]: $3 \mathrm{~A}$

17. Campbell P, Gerich JE (1986) Occurrence of the dawn phenomenon without a change in insulin clearance in patients with insulindependent diabetes mellitus. Diabetes 35: 749-752

18. Widmer A, Keller U, Pasquel U, Berger W (1988) Alterations in insulin clearance and hepatic blood flow during the night do not contribute to the dawn phenomenon in type 1 diabetes. Horm Res 29: 197-201

19. Bolli GB (1988) The dawn phenomenon: its origin and contribution to early morning hyperglycaemia in diabetes mellitus. Diab Metab 14:675-686

20. Cryer P, Gerich J (1985) Glucose counterregulation, hypoglycemia, and intensive insulin therapy. N Engl J Med 313: 232-241 
21. Bolli GB (1989) The pharmacokinetics basis of insulin therapy in diabetes mellitus. Diab Res Clin Pract 6: S3-S16

22. Faber O, Binder C (1985) C-peptide response to glucagon: a test for the residual B-cell function in diabetes mellitus. Diabetes 26: 605-610

23. Trivelli LA, Ranney HM, Lai HT (1971) Haemoglobin components in patients with diabetes mellitus. $\mathrm{N}$ Engl $\mathrm{J}$ Med 284: 353-357

24. Bolli G, De Feo P, Compagnucci P, Cartechini MG, Angeletti G, Santeusanio F, Brunetti P (1982) Important role of adrenergic mechanisms in acute glucose counterregulation following insulin-induced hypoglycemia in type 1 diabetes: evidence foran effect mediated by beta-adrenoreceptors. Diabetes 31: 641-647

25. Bolli G, De Feo P, Compagnucci P, Cartechini MG, Angeletti G, Santeusanio F, Brunetti P, Gerich JE (1983) Abnormal glucose counterregulation in insulin-dependent diabetes mellitus. Interaction of anti-insulin antibodies and impaired glucagon and epinephrine secretion. Diabetes 32: 134-141

26. De Feo P, Bolli G, Perriello G, De Cosmo S, Compagnucci P, Angeletti $G$, Santeusanio F, Gerich JE, Motolese M, Brunetti $P$ (1983) The adrenergic contribution to glucose counterregulation in type 1 diabetes mellitus: dependency on A-cell function and mediation through beta-2-adrenergic receptors. Diabetes 32: 887-893

27. Bolli G, De Feo P, Perriello G, De Cosmo S, Compagnucci P, Santeusanio F, Brunetti P, Unger RH (1984) Mechanisms of glucagon secretion during insulin-induced hypoglycemia in man: role of beta-cell and arterial hyperinsulinemia. J Clin Invest 73: 917-922

28. Bolli G, De Feo P, De Cosmo S, Perriello G, Ventura MM, Massi Benedetti M, Santeusanio F, Gerich JE, Brunetti P (1984) A reliable and reproducible test for adequate glucose counterregulation in type 1 (insulin-dependent) diabetes mellitus. Diabetes 33: $732-737$

29. Bolli G, De Feo P, De Cosmo S, Perriello G, Angeletti G, Ventura MM, Santeusanio F, Brunetti P, Gerich JE (1984) Effects of long-term optimization and short-term deterioration of glycemic control on glucose counterregulation in type 1 (insulin-dependent) diabetes mellitus. Diabetes 33:394-400

30. Bolli GB, Perriello G, De Feo P, Ventura MM, Calafiore R, Calcinaro F, Brunetti $P$ (1987) La resistenza insulinica nel diabate mellito di tipo 1. Effetti della terapia insulinica. Atti 11 Congr Naz Soc Ital Diabetol, Monduzzi, Bologna, pp 33-44

31. Perriello G, Torlone E, Di Santo S, Fanelli C, De Feo P, Santeusanio F, Brunetti P, Bolli GB (1988) Effect of storage temperature of insulin on pharmacokinetics and pharmacodynamics of insulin mixtures injected subcutaneously in subjects with Type 1 (insulin-dependent) diabetes mellitus. Diabetologia 31: 811-815

32. Mc Guire E, Helderman J, Tobin R, Andres R, Berman M (1976) Effects of arterial versus venous sampling on analysis of glucose kinetics in man. $\mathrm{J}$ Appl Physiol 41: 565-573

33. Compagnucci P, Cartechini MG, Bolli G, De Feo P, Santeusanio F, Brunetti P (1981) The importance of determing irreversiblyglycosilated haemoglobin in diabetics. Diabetes 30: 607-612

34. Andres R, Swerdloff I, Pozefsky T, Coleman D (1986) Normal feedback technique for the control of blood glucose concentration. In: Skeggs LT Jr (ed) Automation in analytical chemistry. Mediad, New York, pp 486-491

35. Rizza RA, Cryer PE, Gerich JE (1979) Role of glucagon, catecholamines, and growth hormone in human glucose counterregulation: effects of somatostatin and combined $a-$ and $b-$ adrenergic blockade on plasma glucose recovery and glucose flux rates after insulin-induced hypoglycemia. J Clin Invest 64: 62-71

36. Kuzuya H, Blix PM, Horwitz DL, Steiner DF, Rubenstein AH (1977) Determination of free and total insulin and C-peptide in insulin-treated diabetics. Diabetes 26: 22-29
37. De Bodo R, Steele R, Altzuler N, Dunn A, Bishop J (1963) On the hormonal regulation of carbohydrate metabolism: studies with C 14 glucose. Rec Progr Horm Res 19: 445-448

38. Miles J, Haymond M, Gerich JE (1982) Effects of free fatty acids, insulin, glucagon, and adrenaline on ketone body production in humans. In: Metabolic Acidosis, Ciba Foundation Symposium 87. Pitman Books, London, pp 192-213

39. Cobelli C, Mari A, Ferrannini E (1987) The non-steady state problem: error analysis of Steele's model and new developments for glucose kinetics. Am J Physiol 252: E679-E689

40. De Fronzo RA (1988) The triumvirate: B-cell, muscle, liver. A collusion responsible for NIDDM. Diabetes 37: 667-687

41. Zar J (1984) Statistical analysis. Prentice Hall, Englewood Cliffs, NJ

42. Kerner W, Navaascués I, Torres AA, Pfeiffer EF (1984) Studies on the pathogenesis of the dawn phenomenon in insulin-dependent diabetic patients. Metabolism 33:458-464

43. Skor DA, White NH, Thomas L, Shah SD, Cryer PE, Santiago JV (1983) Examination of the role of the pituitary-adrenocortical axis, counterregulatory hormones, and insulin clearance in variable nocturnal insulin requirements in insulin-dependent diabetes. Diabetes 32: 403-407

44. Campbell PJ, Bolli GB, Gerich JE (1988) Prevention of the dawn phenomenon (early morning hyperglycemia) in insulin-dependent diabetes mellitus by bedtime intranasal administration of a long-acting somatostatin analog. Metabolism 37: 34-37

45. Brennan JR, Gebhart SSP, Blackard WG (1985) Pump-induced insulin aggregation: a problem with the Biostator. Diabetes 34: 353-359

46. Clore JN, Nestler JE, Blackard WG (1989) Sleep-associated fall in glucose disposal and hepatic glucose output in normal humans: putative signaling mechanism linking peripheral and hepatic events. Diabetes 38: 285-290

47. Trovati M, Lorenzati R, Carta Q, Cavalot F, Vitali S, Caselle MT, Pagani A, Pagano G, Lenti G (1982) Overnight changes in insulin requirements assessed by the artificial pancreas in insulin-dependent male diabetics. IRCS Med Sci 10:368-369

48. Calabrese G, Bueti A, Santeusanio F, Giombolini A, Zega G, Angeletti G, Cartechini MG, Brunetti P (1982) Continuous subcutaneous insulin infusion treatment in insulin-dependent diabetic patients: a comparison with conventional optimized treatment in a long-term study. Diabetes Care 5: 457-465

49. Yki-Yarvinen H, Koivisto VA (1986) Natural course of insulin resistance in type I diabetes. $N$ Engl $\mathbf{J}$ Med 315:224-230

50. Unger R, Grundy S (1985) Hyperglycaemia as an inducer as well as a consequence of impaired islet function and insulin resistance: implication for the management of diabetes. Diabetologia 28: 119-121

51. Bending JJ, Pickup JC, Collins ACG, Keen H (1985) Rarity of a marked "dawn phenomenon" in diabetic subjects treated by continuous subcutaneous insulin infusion. Diabetes Care 8: 28-33

52. Gale EAM, Kurtz AB, Tattersall RB (1980) In search of the Somogyi effect. Lancet II: 279-282

53. Francis AJ, Home PD, Hanning I, Alberti KGMM, Turnbridge WMG (1983) Intermediate acting insulin given at bedtime: effect on blood glucose concentrations before and after breakfast. $\mathrm{Br}$ Med J 286: 1173-1176

Received: 11 January 1990

and in revised form: 26 June 1990

Prof. G.B. Bolli

Istituto di Patologia Medica

dell'Universita'

Via E.Dal Pozzo

I-06100 Perugia

Italy 